\title{
Morfologia e grânulos citoplasmáticos do corpo lúteo de vacas aneloradas (Bos taurus indicus) gestantes e não gestantes
}

\author{
[Morphology and cytoplasmic granules of the corpus luteum in pregnant \\ and non-pregnant Nelore cows] \\ L.R. Vargas $^{l}$, P.R. Xavier ${ }^{l}$, C.A. Rezende ${ }^{l}$, M.M. Neves ${ }^{2}$, A.P. Marques Júnior ${ }^{3,4 *}$ \\ ${ }^{1}$ Aluna de pós-graduação - Escola de Veterinária - UFMG - Belo Horizonte, MG \\ ${ }^{2}$ Universidade Federal de Viçosa - Viçosa, MG \\ ${ }^{3}$ Escola de Veterinária - UFMG - Belo Horizonte, MG \\ ${ }^{4}$ Bolsista de Produtividade - CNPq \\ RESUMO
}

\begin{abstract}
Avaliaram-se a proporção volumétrica dos constituintes do corpo lúteo e a distribuição de células lúteas com grânulos citoplasmáticos no corpo lúteo de animais Nelore ao longo da gestação e em animais não gestantes. Foram coletados ovários com corpos lúteos de 24 animais abatidos em frigorífico. Os animais foram distribuídos em dois grupos: gestantes e não gestantes. A idade gestacional foi determinada pela medição do comprimento apicocaudal do feto. Os ovários foram distribuídos segundo o trimestre gestacional: primeiro - gestação de até 90 dias; segundo - de 91 a 180 dias; e terceiro - de 181 a 270 dias. Os corpos lúteos, processados para inclusão em paraplast, foram avaliados em microscópio de luz. Na proporção volumétrica do corpo lúteo, os constituintes avaliados foram citoplasma e núcleo de células lúteas, tecido conjuntivo e fibroblastos, células endoteliais e pericitos e vasos sanguíneos. A proporção volumétrica de citoplasma de células lúteas reduziu de $46,1 \pm 2,8 \%$ para $37,9 \pm 3,5 \%$ e a de núcleo de células lúteas reduziu de $9,2 \pm 1,0 \%$ para $6,2 \pm 1,0 \%$, do primeiro para o segundo trimestre. A proporção de tecido conjuntivo e fibroblastos aumentou de $20,9 \pm 5,4 \%$, no primeiro trimestre, para $34,0 \pm 4,2 \%$, no segundo trimestre. Grânulos citoplasmáticos foram evidenciados pelas técnicas histoquímicas xylidine ponceau e azul de bromofenol, que indicam sua provável composição proteica. A quantidade de células maiores com grânulos aumentou significativamente de 2,3 $31,9 \%$, no primeiro trimestre, para $25,5 \pm 20,3 \%$, no segundo. A proporção volumétrica de citoplasma e núcleo de células lúteas diminuiu ao longo da gestação, e a de tecido conjuntivo aumentou. A quantidade de células lúteas maiores contendo grânulos também aumentou ao longo da gestação.
\end{abstract}

Palavras-chave: Nelore, corpo lúteo, histologia, grânulos citoplasmáticos

\begin{abstract}
The purpose of this study was to evaluate, in cycling and pregnant Nelore cows, the volumetric proportion of the corpus luteum and the distribution of lutein cells with cytoplasmic granules. Twenty four ovaries with corpus luteum were collected in a slaughterhouse. The ovaries were distributed into two groups: pregnant and non-pregnant cows. The group of pregnant cows was divided according to the stage of pregnancy, by the crown-rump fetus length: $1^{\text {st }}$ third - until 90 days, $2^{\text {nd }}$ third - between 91 and 180 days and $3^{\text {rd }}$ third - between 181 and 270 days. The corpus luteum were processed for inclusion in paraplast, and slides were stained for analysis in light microscopy. The constituents quantified in the volumetric proportion were: lutein cells cytoplasm and nucleus, connective tissue and fibroblasts, endothelial cells and pericyte and blood vessels. The volumetric proportion of lutein cells cytoplasm decreased significantly from $46.1 \pm 2.8 \%$ to $37.9 \pm 3.5 \%$, and also decreased significantly in the nucleus from $9.2 \pm 1.0 \%$ to $6.2 \pm 1.0 \%$ between the first and the second trimester of pregnancy. The amount of
\end{abstract}

Recebido em 4 de abril de 2014

Aceito em 25 de novembro de 2014

*Autor para correspondência (corresponding author)

E-mail: ampinho@ufmg.br 
connective tissue and fibroblasts increased significantly throughout gestation, with $20.9 \pm 5.4 \%$ on the first trimester and $34.0 \pm 4.2 \%$ on the second. Granules were evidenced by the histochemical technique of Xylidine Ponceau and Bromophenol blue, indicating their probable protein composition. The amount of lutein cells with granules increased throughout gestation, but significant difference was observed only between the first $(2.3 \pm 1.9 \%)$ and second trimester $(25.5 \pm 20.3 \%)$. The cytoplasmic and nucleus volumetric proportion decreased during pregnancy and the volumetric proportion of connective tissue increased. The amount of lutein cells with granules increased throughout pregnancy.

Keywords: Nelore cow, corpus luteum, histology, cytoplasmic granules

\section{INTRODUÇÃO}

O corpo lúteo é uma glândula endócrina ovariana transitória, que secreta progesterona durante a fase lútea do ciclo estral e durante a gestação (Rodgers et al., 1988). A progesterona é essencial na manutenção da gestação (Siiteri e Stites, 1982) e, em animais não gestantes, regula o comprimento do ciclo estral (McCracken et al., 1999).

O corpo lúteo apresenta $67,9 \%$ de seu volume ocupado por células esteroidogênicas, constituídas pelas células lúteas maiores e pelas células lúteas menores. As células lúteas maiores apresentam formato esférico ou poliédrico, com núcleo grande e arredondado e nucléolo proeminente, e se originam das células da granulosa do folículo ovulatório e das células lúteas menores, o que justifica o aumento da quantidade de células lúteas maiores ao longo da vida do corpo lúteo (O'Shea et al., 1989). Contêm grânulos densos dispersos no citoplasma tanto no corpo lúteo cíclico quanto no gestacional (Alila e Hansel, 1984) e são responsáveis pela produção de pelo menos $80 \%$ da progesterona proveniente do corpo lúteo (Niswender et al., 1985). Já as células lúteas menores apresentam forma estrelada, citoplasma mais escuro que as células lúteas maiores (Senger, 2003), 10 a $20 \mu \mathrm{m}$ de diâmetro, e são provenientes das células da teca interna (Hansel et al., 1987).

A distribuição e o conteúdo dos grânulos citoplasmáticos das células lúteas em animais gestantes ainda não são bem conhecidos. Fields et al. (1992) observaram que grânulos secretórios citoplasmáticos ocorrem nas células lúteas maiores e menores, contudo apenas as células maiores possuem estes em abundância. Já Kohsaka et al. (2001) descreveram as células lúteas maiores como as únicas que contêm grânulos secretórios citoplasmáticos no corpo lúteo.

Segundo Fields et al. (1992) e Kohsaka et al. (2001), existem pelo menos três populações distintas de grânulos nas células luteais maiores. A primeira contém ocitocina e é observada ao longo do ciclo estral e até os 25 dias de gestação. A segunda população de grânulos, composta por grânulos pequenos, começa a se formar após os 45 dias de gestação, atingindo pico entre os dias 180 e 210, e sua composição não é conhecida. Já a terceira, composta por grânulos de relaxina, ou grânulos grandes, apresenta-se escassa aos quatro meses de gestação, aumenta após o sétimo mês e apresenta pico próximo ao parto.

O conhecimento sobre a morfologia e a fisiologia do corpo lúteo da vaca Nelore é fundamental no desenvolvimento e na melhoria de biotecnias reprodutivas que envolvem o controle do ciclo estral e da ovulação ideais para essa raça. Existem diferenças fisiológicas entre o corpo lúteo cíclico e o gestacional na espécie bovina. Contudo, há pouca informação sobre o corpo lúteo gestacional da vaca Nelore, o que motivou a realização deste experimento.

O objetivo deste estudo foi avaliar a proporção volumétrica e a presença e distribuição de grânulos citoplasmáticos nas células luteais do corpo lúteo da vaca Nelore ao longo da gestação e em animais não gestantes.

\section{MATERIAL E MÉTODOS}

O experimento foi aprovado pela Comissão de Ética no Uso de Animais (CEUA/UFMG), sob o protocolo ${ }^{\circ}$. 247/2013.

Aparelhos reprodutivos de fêmeas Nelore foram coletados logo após o abate, no frigorífico Santa Vitória, no município de Contagem, MG, e avaliados em relação ao estádio fisiológico, 
como gestantes ou não gestantes. Ovários que continham corpos lúteos funcionais foram coletados e pré-fixados em formalina neutra tamponada a $10 \%$ por período inferior a quatro horas.

A determinação do período gestacional foi feita com base na medida do comprimento apicocaudal dos fetos, utilizando-se a fórmula proposta por Richardson (1996): $X=2,5(Y+$ $21)$, em que $X$ é a variável idade da gestação (dias) e $Y$ representa o comprimento apicocaudal (cm).

Com base na avaliação do estádio fisiológico do animal, os ovários foram divididos em dois grupos: ovários de animais gestantes e ovários de não gestantes. Após a medição do comprimento apicocaudal do feto, foi feita a separação dos ovários de animais gestantes em grupos segundo o trimestre da gestação: $1^{\circ}$ terço - gestação de até 90 dias (seis animais); $2^{\circ}$ terço - gestação de 91 a 180 dias (seis animais); e $3^{\circ}$ terço gestação de 181 a 270 dias (seis animais). O grupo de animais não gestantes também foi composto por seis animais, de forma que o experimento utilizou ovários de um total de 24 animais.

Os corpos lúteos foram dissecados dos ovários e fixados em formalina neutra tamponada por 48 horas; em seguida, permaneceram em solução de álcool a $70 \%$ até o momento do processamento histológico. Os tecidos foram incluídos em paraplast (Paraplast Plus ${ }^{\circledR}$, paraplast, Sigma, EUA), segundo a metodologia descrita por Michalany (1980), e cortados em micrótomo manual com $3 \mu$ de espessura. Foram feitas as colorações hematoxilina-eosina, tricrômico de Gomori, xylidine ponceau e azul de bromofenol.
A proporção volumétrica dos constituintes do corpo lúteo foi avaliada em lâminas coradas em hematoxilina-eosina. Os componentes observados foram citoplasma e núcleo de células lúteas maiores e menores, células endoteliais e pericitos, tecido conjuntivo e fibroblastos e vasos sanguíneos. As proporções volumétricas foram obtidas pelo método estereométrico, utilizandose ocular integradora Zeiss KPL 10x, com retículo de cinco linhas horizontais e 25 pontos equidistantes, acoplada a uma objetiva de 40x. Foram examinados aleatoriamente 35 campos por lâmina, em varredura horizontal. Os resultados foram expressos em porcentagem sobre um total de 875 pontos por corpo lúteo (Neves et al., 2002).

Lâminas coradas em tricrômico de Gomori foram utilizadas na avaliação da presença e da distribuição de grânulos citoplasmáticos em células lúteas. Foram contabilizadas 200 células lúteas por corpo lúteo em campos aleatórios em varredura horizontal (Mandarim de Lacerda, 1995), utilizando-se a ocular integradora Zeiss KPL 10x, com retículo de cinco linhas horizontais e 25 pontos equidistantes, acoplada a uma objetiva de 40x. A característica histoquímica dos grânulos foi avaliada em lâminas coradas em xylidine ponceau e azul de bromofenol.

O delineamento experimental foi inteiramente ao acaso. Realizou-se análise das médias por estatística descritiva e análise de variância.

\section{RESULTADOS E DISCUSSÃO}

Os resultados da proporção volumétrica do corpo lúteo de animais gestantes, nos três terços da gestação, e de não gestantes estão apresentados na Tab. 1.

Tabela 1. Médias e desvios padrão da proporção volumétrica dos constituintes do corpo lúteo de vacas Nelore gestantes e não gestantes

\begin{tabular}{llllll}
\hline Grupo & \multicolumn{1}{c}{ CCL } & NCL & \multicolumn{1}{c}{ CEP } & TCF & VS \\
\hline $1^{\circ}$ trimestre & $46,13 \pm 2,84 \mathrm{a}$ & $9,16 \pm 1,03 \mathrm{a}$ & $2,97 \pm 1,53 \mathrm{ab}$ & $20,93 \pm 5,39 \mathrm{a}$ & $7,65 \pm 6,32 \mathrm{a}$ \\
$2^{\circ}$ trimestre & $37,88 \pm 3,50 \mathrm{~b}$ & $6,21 \pm 1,02 \mathrm{~b}$ & $4,22 \pm 1,66 \mathrm{a}$ & $34,04 \pm 4,17 \mathrm{~b}$ & $4,49 \pm 2,91 \mathrm{a}$ \\
$3^{\circ}$ trimestre & $38,46 \pm 3,08 \mathrm{~b}$ & $6,04 \pm 1,32 \mathrm{~b}$ & $1,79 \pm 0,85 \mathrm{~b}$ & $34,61 \pm 2,48 \mathrm{~b}$ & $4,19 \pm 1,30 \mathrm{a}$ \\
Não gestante & $40,91 \pm 3,85 \mathrm{ab}$ & $6,64 \pm 1,08 \mathrm{~b}$ & $2,26 \pm 1,96 \mathrm{~b}$ & $36,76 \pm 2,51 \mathrm{~b}$ & $5,73 \pm 3,91 \mathrm{a}$ \\
\hline
\end{tabular}

Médias com letras diferentes na mesma coluna diferem estatisticamente pelo teste de Tukey $(\mathrm{p}<0,05)$.

$1^{\circ}$ trimestre: 0-90 dias de gestação; $2^{\circ}$ trimestre: 91-180 dias de gestação; $3^{\circ}$ trimestre: 181-270 dias de gestação; CCL - citoplasma de células lúteas; NCL - núcleo de células lúteas; CEP - células endoteliais e pericitos; TCF tecido conjuntivo e fibroblastos; VS - vasos sanguíneos. 
Houve redução no volume do corpo lúteo ocupado por citoplasma e núcleo de células lúteas do primeiro para o segundo terço, concomitantemente a um aumento na proporção volumétrica de tecido conjuntivo. Esse resultado é compatível com o processo natural de regressão luteal na gestação, no qual se observa declínio na proporção de células esteroidogênicas e substituição dessas por tecido conjuntivo. Segundo Fields e Fields (1996), somente a partir dos 200 dias de gestação é que se observa considerável declínio na proporção de células lúteas em decorrência da luteólise, contudo, no presente estudo, essa redução foi observada na transição do primeiro para o segundo terço da gestação.

A maior proporção volumétrica de vasos sanguíneos foi observada no primeiro terço da gestação, contudo não houve diferença significativa entre os quatro grupos. Essa ocorrência é compatível com o trabalho de Hojo et al. (2009), que observaram maior expressão de fatores angiogênicos durante a fase de desenvolvimento do corpo lúteo em relação à fase madura, o que poderia justificar a maior proporção de vasos sanguíneos no primeiro terço gestacional. Ainda, foi observada maior proporção de células endoteliais e pericitos no segundo terço da gestação. Houve redução, com diferença significativa, entre o segundo terço e o terceiro, e entre o segundo e o grupo de não gestantes. A redução da proporção de células endoteliais e pericitos verificada entre o segundo e o terceiro terço é compatível com o processo de luteólise, que se inicia com a redução do fluxo sanguíneo luteal. Xavier et al. (2011) encontraram redução, com diferença estatística, quando compararam a proporção de células endoteliais e pericitos entre o primeiro e segundo terços apenas.

As técnicas histoquímicas xylidine ponceau e azul de bromofenol, utilizadas para evidenciar estruturas de composição proteica no tecido luteal, foram eficientes em evidenciar grânulos citoplasmáticos em células lúteas, o que indica a provável constituição proteica desses grânulos (Fig. 1). Grânulos citoplasmáticos foram observados apenas no citoplasma de células lúteas maiores (Fig. 2). O resultado da contagem de células lúteas contendo grânulos citoplasmáticos está disposto na Tab. 2 .

Foi observado aumento numérico gradual da quantidade de células com grânulos do início para o final da gestação, com diferença significativa apenas entre o primeiro e os outros terços. Esse resultado foi semelhante ao encontrado por Xavier et al. (2012), que verificaram que esses grânulos estão presentes em maior quantidade ao final do segundo terço e durante o terceiro terço da gestação. A ausência de grânulos citoplasmáticos em células lúteas menores sugere que essas células apresentam menor atividade em relação as células maiores e talvez menor participação no processo de luteólise e na manutenção da gestação.

No tecido luteal dos animais não gestantes avaliados, foram encontradas apenas duas células contendo grânulos citoplasmáticos. Tal resultado sugere que o conteúdo desses grânulos não seria importante durante o ciclo estral, mas apenas durante a gestação, quando estão presentes em maior quantidade. Esse achado indica que os grânulos observados não contêm ocitocina, pois normalmente são observados ao longo de todo o ciclo estral. É possível que, em animais não gestantes, o corpo lúteo não apresente tempo de vida suficientemente longo para a produção desses grânulos de natureza proteica, ou a função dos grânulos não seria importante durante o ciclo estral, mas apenas durante a gestação, quando estão presentes em maior quantidade.

Apesar de a técnica utilizada neste trabalho não ter possibilitado a diferenciação de grânulos maiores e menores, é provável que os grânulos encontrados representem a população de grânulos pequenos descrita por Fields et al. (1992), pois foram observados em todos os trimestres da gestação e praticamente não foram visualizados no tecido luteal de animais não gestantes. Segundo Fields $e t$ al. (1985), grânulos semelhantes observados no corpo lúteo de porcas contêm relaxina, e já foi detectada reação positiva pela imuno-histoquímica para relaxina no corpo lúteo bovino ao final da gestação. Contudo, foi demonstrado que a relaxina do corpo lúteo gestacional da vaca está contida apenas nos grânulos maiores; o conteúdo dos grânulos pequenos permanece desconhecido (Kohsaka et al., 2001). É possível que esses grânulos participem de algum processo fisiológico endócrino importante na manutenção da gestação ainda não conhecido. A maior quantidade de células com grânulos ao final da gestação pode ser ainda um indício de que esses grânulos estejam envolvidos no processo de luteólise ou parto. 

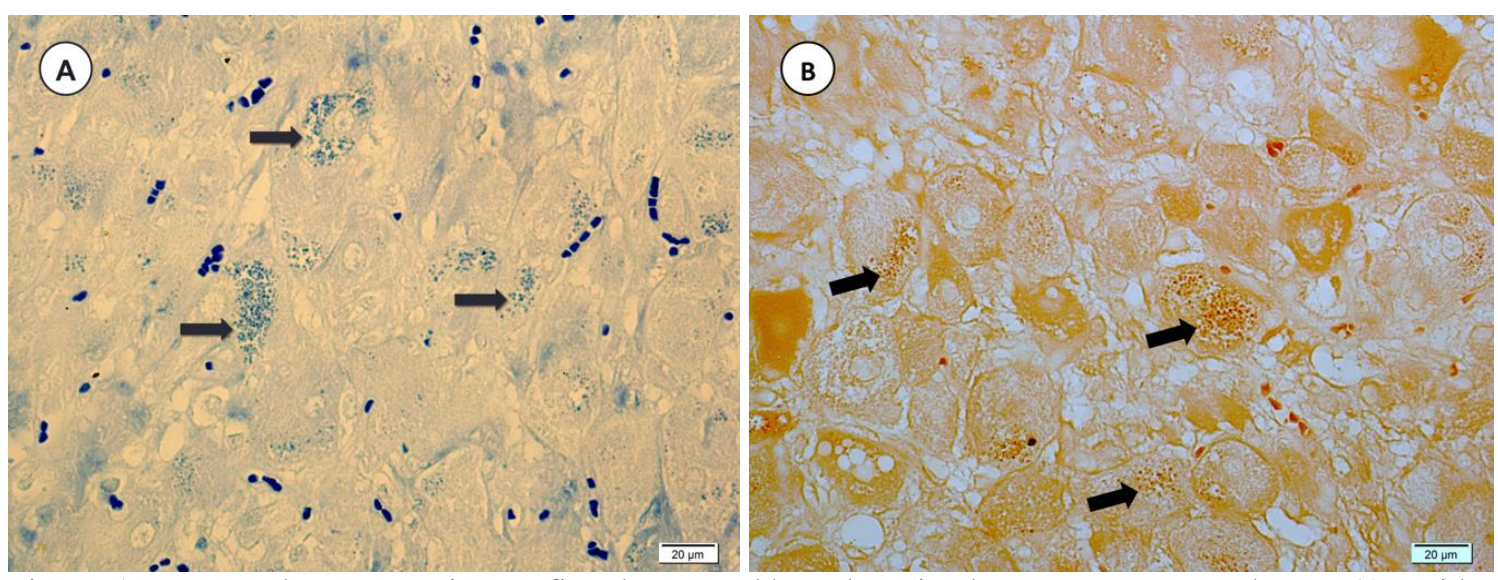

Figura 1. Vaca Nelore. Fotomicrografias de corpo lúteo de animal gestante, mostrando em A) tecido luteal aos 218 dias de gestação ( $3^{\circ}$ terço); coloração: azul de bromofenol. Em B) tecido luteal aos 275 dias de gestação ( $3^{\circ}$ terço), com células lúteas contendo grânulos citoplasmáticos (seta); coloração: xylidine ponceau.

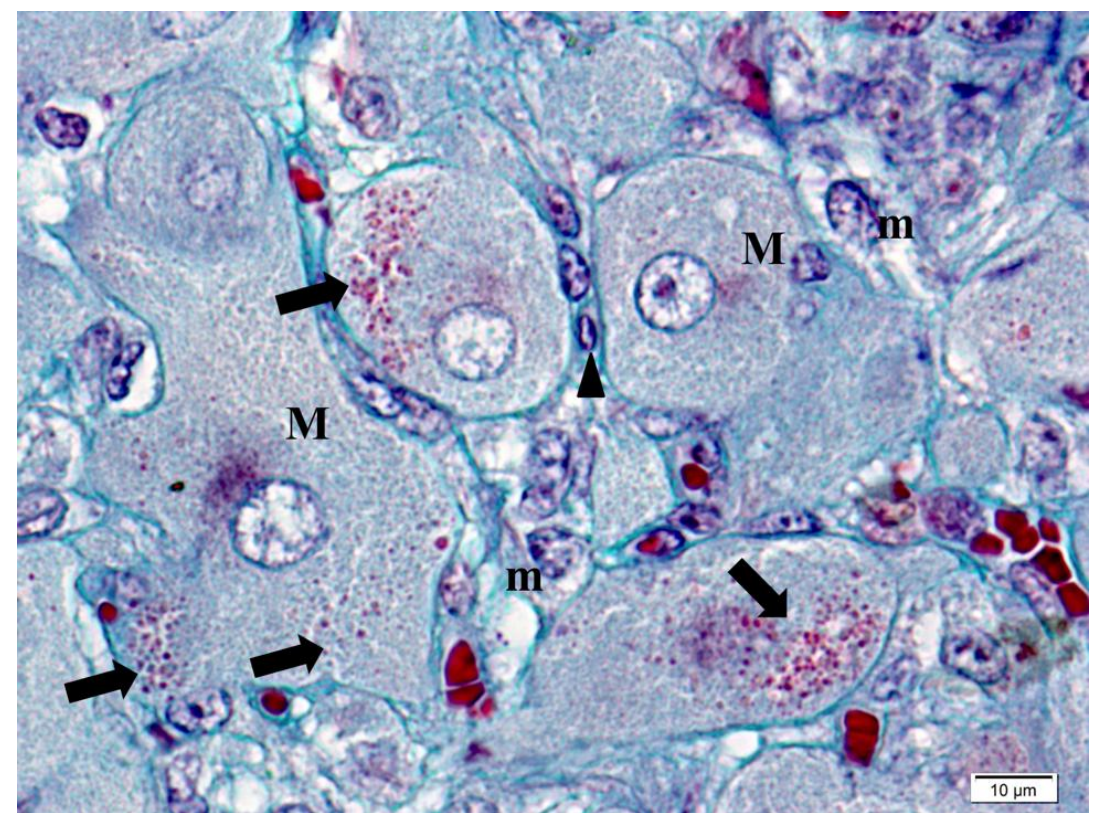

Figura 2. Vaca Nelore. Fotomicrografia de corpo lúteo de animal gestante. Tecido luteal aos 218 dias de gestação $\left(3^{\circ}\right.$ terço) com células lúteas maiores $(\mathrm{M})$ e menores $(\mathrm{m})$, grânulos citoplasmáticos em células lúteas maiores (seta) e fibroblastos circundando células lúteas (cabeça de seta). Coloração: tricrômico de Gomori.

Tabela 2. Total de células lúteas maiores e menores do corpo lúteo de animais gestantes e não gestantes que contêm ou não contêm grânulos no citoplasma, sob um total de 200 células

\begin{tabular}{lcccc} 
& \multicolumn{2}{c}{ Célula lútea maior } & \multicolumn{2}{c}{ Célula lútea menor } \\
\hline Grupo & Com grânulos & Sem grânulos & Com grânulos & Sem grânulos \\
$1^{\circ}$ trimestre & $2,33 \pm 1,94 \mathrm{a}$ & $78,5 \pm 7,55 \mathrm{ab}$ & 0 & $19,17 \pm 7,46 \mathrm{a}$ \\
$2^{\circ}$ trimestre & $25,50 \pm 20,34 \mathrm{~b}$ & $56,50 \pm 20,82 \mathrm{bc}$ & 0 & $18,00 \pm 2,85 \mathrm{a}$ \\
$3^{\circ}$ trimestre & $39,75 \pm 25,07 \mathrm{~b}$ & $38,17 \pm 18,63 \mathrm{c}$ & 0 & $18,75 \pm 3,25 \mathrm{a}$ \\
Não gestante & $0,17 \pm 0,26 \mathrm{c}$ & $82,42 \pm 7,43 \mathrm{a}$ & 0 & $17,42 \pm 7,36 \mathrm{a}$ \\
\hline
\end{tabular}

Médias com letras diferentes na mesma coluna diferem pelo teste de Tukey $(\mathrm{p}<0,05)$. $1^{\circ}$ terço: 0-90 dias de gestação; $2^{\circ}$ terço: 91-180 dias de gestação; $3^{\circ}$ terço: 181-270 dias de gestação. 


\section{CONCLUSÕES}

A proporção volumétrica de citoplasma e núcleo de células lúteas diminuiu ao longo da gestação, enquanto do primeiro para o segundo trimestre houve aumento de tecido conjuntivo, assim como da quantidade de células lúteas maiores contendo grânulos citoplasmáticos.

\section{AGRADECIMENTOS}

À Capes, pela concessão da bolsa de mestrado; ao CNPq, pela concessão do grant ao orientador; à professora Mariana Machado Neves e sua equipe do Laboratório de Morfologia da UFV, pela acolhida e pela colaboração; ao Frigorífico Santa Vitória, pela disponibilização dos espécimes utilizados.

\section{REFERÊNCIAS}

ALILA, H.W.; HANSEL, W. Origin of different cell types in the bovine corpus luteum as characterized by specific monoclonal antibodies. Biol. Reprod., v.31, p.1015-1025, 1984.

FIELDS, M.J.; BARROS, C.M.; FIELDS, P.A. Characterization of large luteal cells and they secretory granules during the estrous cycle of the cow. Biol. Reprod., v.46, p.535-545, 1992.

FIELDS, M.J.; DUBOIS, W.; FIELDS, P.A. Dynamic features of luteal secretory granules: ultrastructural changes during the course of pregnancy in the cow. Endocrinology, v.117, p.1675-1682, 1985.

FIELDS, M.J.; FIELDS, P.A. Morphological characteristics of the bovine corpus luteum during the estrus cycle and pregnancy. Theriogenology, v.45, p.1295-1325, 1996.

HANSEL, W.; ALILA, H.W.; DOWD, J.P. et al. Control of steroidogenesis in small and large bovine luteal cells. Aust. J. Biol. Sci., v.40, p.331-347, 1987.

HOJO, T.; AL-ZI'ABI, M.O.; SKARZYNSKI, D.J. et al. Changes of the vasculature of bovine corpus luteum during the estrous cycle and prostaglandin F2 $\alpha$-induced luteolysis. J. Reprod. Dev., v.55, p.512517, 2009.

KOHSAKA, T.; SASADA, H.; SATO, E. et al. Ultrastructural properties and immunolocalization of relaxin in the cytoplasmatic electron-dense granules of large luteal cells during pregnancy in the cow. $J$. Reprod. Dev., v.47, p.218-225, 2001.
MANDARIM DE LACERDA, C.A. Métodos quantitativos em morfologia. Rio de Janeiro: UERJ, 1995. 131p.

MCCRACKEN, J.A.; CUSTER, E.E.; LAMSA, J.C. Luteolysis: a neuroendocrine-mediated event. Physiol. Rev., v.79, p.263-323, 1999.

MICHALANY, J. Técnica histológica em anatomia patológica: com instruções para o cirurgião, enfermeira e citotécnico. 1.ed. São Paulo: EPU, 1980. $277 \mathrm{p}$.

NEVES, M.M.; MARQUES JR, A.P.; SANTANA, C.V. et al. Características de ovários de fêmeas Zebu (Bos taurus indicus), colhidos em abatedouros. Arq. Bras. Med. Vet. Zootec., v.54, p.651-654, 2002.

NISWENDER, G.D.; SCHAWALL, R.H.; FITZ, T.A. et al. Regulation of luteal function in domestic ruminant: new concepts. Recent. Prog. Horm. Res., v.41, p.101-151, 1985.

O'SHEA, J.D.; RODGERS, R.J.; D'OCCHIO, M.J. Cellular composition of the cyclic luteum of the cow. J. Reprod. Fertil., v.85, p.483-487, 1989.

RICHARDSON, C. Personal communication. The development of the conceptus. In: ARTHUR, G.H.; PERKINSON, T.J. (Ed). Veterinary Reproduction and Obstetrics. 8.ed. London: WB Soundres, 1996. p.68.

RODGERS, R.J.; MITCHELL, M.D.; SIMPSON, E.R. Secretion of progesterone and prostaglandins by cells of bovine corpora lutea from three stages of the luteal phase. J. Endocrin., v.118, p.121-126, 1988.

SIITERI, P.K.; STITES, D.P. Immunologic and endocrine interrelationships in pregnancy. Biol. Reprod., v.26, p.1-14, 1982.

SENGER, P.L. Reproductive cyclicity - The Luteal Phase. In: Pathways to Pregnancy and Parturition. 2nd ed. Washington: Current Conceptions, 2003. cap.9, p.188-213.

XAVIER, P.R.; LEAO, R.A.C.; OLIVEIRA E SILVA, P.V.D. Histological characteristics of the corpus luteum of Nelore cows in the first, second and third trimester of pregnancy. Arq. Bras. Med. Vet. Zootec., v.64, p.505-509, 2012.

XAVIER, P.R.; MARQUES JÚNIOR, A.P.; LEÃO, R.A.C.; OLIVEIRA E SILVA, P.V.D. Proporção volumétrica dos constituintes do corpo lúteo de vacas Nelore nos terços inicial, médio e final da gestação. Arq. Bras. Med. Vet. Zootec., v.63, p.322-325, 2011. 